\title{
Fosforin reaktiot ja liikkuminen maaperässä
}

\author{
Helinä Hartikainen $^{1)}$ ja Tommi Peltovuori ${ }^{2)}$ \\ 1) Helsingin yliopisto, Soveltavan kemian ja mikrobiologian laitos, helina.hartikainen@helsinki.fi \\ ${ }^{2)}$ Helsingin yliopisto, Soveltavan kemian ja mikrobiologian laitos, tommi.peltovuori@helsinki.fi
}

Maaperän fosforin (P) käyttökelpoisuus kasveille, liikkuminen maaperässä ja vesistöjä rehevöittävä vaikutus riippuu sen esiintymismuodosta sekä veden liikkeistä maassa. Maan fosforireservit voidaan luokitella karkeasti seuraavasti: 1) maanesteessä liukoisena oleva orgaaninen ja epäorgaaninen, 2) hiukkaspinnoille pidättynyt, 3) maan orgaanisen aineksessa oleva, 4) kemiallisesti saostunut ja 5) rapautumattoman kiviaineksen fosfori. Näiden poolien koko ja biologinen käyttökelpoisuus vaihtelee huomattavasti. Käytännössä tämä merkitsee, että lannoitustarpeen ja fosforin aiheuttaman kuormitusriskin arvioinnissa käytettyjen menetelmien antama kuva ja sen luotettavuus maan fosforitilasta voi vaihdella sen mukaan, millaisia reservejä käytetty menetelmä mittaa. Koska eri pooleissa olevan fosforin hyödynnettävyys vaihtelee, yhtä yleisesti hyväksyttyä menetelmää ei ole kyetty kehittämään.

\section{Fosforireservit}

Koska Suomen maaperä on nuorta ja heikosti rapautunutta, rapautumattomassa kiviaineksessa olevat fosforireservit ovat suuret. Kiviaineksen apatiittisilla fosforivarastoilla on kuitenkin melko vähän merkitystä biologisten kiertojen kannalta. Luonnontilaisilla alueilla niistä vapautuu jonkin verran fosforia kasvien käyttöön esim. mykorritsasienten toiminnan kautta, mutta viljelymailla näiden reservien merkitys on vähäinen. Tämän vuoksi fosforilannoitus on ollut tärkeää satotasojen kohottamiseksi. Luonnonprosesseissa vapautuva tai maahan lisätty fosfori joutuu joko kasvien sitomaksi tai sitoutuu maavedestä maahiukkasten pinnoille ns. sekundaariseksi fosforiksi. Liukoisten fosfaattianionien ja hiukkaspinnoilla olevan fosforin välillä vallitsee pyrkimys tasapainoon, mikä on keskeinen biologista saatavuutta ja liikkumista säätelevä mekanismi. Maankäytöstä ja viljelyhistoriasta riippuen hiukkaspinnoille sitoutuneet varastot voivat vaihdella hyvin paljon paitsi eri maiden välillä myös tietyn maan eri kerroksissa.

Orgaaninen fosfori voi muodostaa merkittävän osan viljelymaiden muokkauskerroksen reserveistä: kivennäismailla sitä saattaa olla lähes puolet kokonaisfosforista, turvemailla selvästi enemmän. Orgaanisten reservien kemiallista luonnetta ja biologista käyttökelpoisuutta on Suomessa tutkittu hyvin vähän. Tiedetään kuitenkin, että osa siitä on sitoutuneena varsinaiseen humusainekseen, osa on lannan ja kasvinjätteiden mukana maahan joutunutta. Näiden poolien väliset erot biologisessa käyttökelpoisuudessa voivat olla merkittäviä. Koska varsinainen humus on hyvin hitaasti hajoavaa, sen merkitys kasvien fosforin lähteenä lienee melko vähäinen. Sen sijaan hajoavan orgaanisen aineksen fosfori saadaan käyttökelpoiseen fosfaattimuotoon fosfataasientsyymien vaikutuksesta.

\section{Pidättymisreaktiot}

Kemialliset pidättymisreaktiot säätelevät pitkälti fosforin liikkumista maaperässä. Kasvit joutuvat kilpailemaan maanesteen fosfaatti-ioneista kemiallisten reaktioiden kanssa. Lannoitefosforin kohdalla ongelmana on tehokkaasta sitoutumisesta aiheutuva alhainen hyväksikäyttöaste. Vaikka fosfaatti-ioni on negatiivisesti varattu, se pystyy sitoutumaan spesifisellä mekanismilla negatiivisesti varatuille hiukkaspinnoille päinvastoin kuin esimerkiksi nitraatti, joka on tunnetusti helposti huuhtoutuvaa. Pidätyspintoina toimivat alumiinin ja raudan oksidit, joita syntyy rapautumisen tuotteena. Rapautuminen on pintareaktio ja edistyy sitä tehokkaammin, mitä hienojakoisempaa aines on. Sen vuoksi pidättävää oksidiainesta on runsaimmin savimailla, joiden fosforin sitomiskyky onkin 
tunnetusti suuri. Turvemaissa pidätyspintaa on vähän, koska mineraaliaineksen määrä niissä on pieni. Siksi niitä pitäisi lannoittaa vain hitaasti liukenevilla lannoitteilla.

Myös muut maan kemialliset ominaisuudet vaikuttavat fosforin liikkuvuuteen. Vanhastaan tiedetään, että kalkitus edistää fosforin saatavuutta. Kemiallisesti vaikutus voidaan selittää sillä, että pH:n noustessa oksidipintojen negatiivinen varaus kasvaa, mikä heikentää fosforin sitoutumistaipumusta. Näin ollen suomalaisille maille tyypillinen happamuus on omiaan alentamaan fosforin hyväksikäyttöastetta. Vähemmän huomiota on kiinnitetty liukoisten suolojen vaikutukseen. Maanesteen suolapitoisuuden kasvaessa fosforin pidättyminen tehostuu hiukkaspinnoilla tapahtuvien fysikokemiallisten muutosten seurauksena. Käytännössä tämä merkitsee, että fosforin siirtyminen maavedestä pidätyspinnoille edistyy esim. typpilannoituksen seurauksena. Pidättyminen on aluksi varsin nopeaa; huomattava osa lisätystä fosfaatista sitoutuu jo ensimmäisen vuorokauden aikana. Nopeaa sitoutumista seuraa hidas vaihe, jonka aikana fosforia kulkeutuu oksidien pinnoilta huokoisen oksidiaineksen sisäosiin. Tämän kuukausia tai jopa vuosia kestävän reaktiovaiheen seurauksena on, että osa lisätystä fosforista sitoutuu muotoon, josta kasvit eivät voi sitä käytännöllisesti katsoen hyödyntää.

Pohjoisissa oloissa myös maan lämpötilalla voi olla merkitystä fosforin käyttökelpoisuuden kannalta. Äskettäin on saatu mielenkiintoisia tuloksia, joiden mukaan lämpötilan aletessa pidättymisreaktiot hidastuvat, mutta maan jäätyessä pidättyminen voi äkisti kasvaa (Soinne 2000). Ilmiötä selittäviä tekijöitä tutkitaan parhaillaan. Näyttää siltä, että routaantumisen vaikutus liittyy nimenomaan maaveden suolapitoisuudessa tapahtuviin muutoksiin. Lämpötilan laskiessa $0^{\circ} \mathrm{C}: n$ alapuolelle ensin jäätyy puhdas vesi ja jäätymättä jäävän maaveden suolapitoisuus kasvaa. Jos liuosfaasin fosforipitoisuus on riittävän suuri, korkea suolapitoisuus edistää pidättymistä oksidipinnoille. Sitoutumisen hidastuminen lämpötilan aletessa tuskin on hyödyksi kasvien fosforin oton kannalta, sillä samalla niiden kasvu ja aktiivinen ravinteiden otto hidastuvat. Jäätymisen aiheuttama pidättymisen tehostuminen puolestaan voi vähentää fosforin käyttökelpoisuutta seuraavana kasvukautena. Roudan vaikutusta syyslannoituksena annetun fosforin tehokkuuteen olisikin syytä tutkia tarkemmin.

Orgaaniset fosforiyhdisteet eivät ole kasvien käytettävissä ennen kuin ne ovat hajonneet mikrobiologisissa reaktioissa fosfaateiksi. Tällöin niiden kohtaloa säätelevät samat tekijät kuin epäorgaanisen fosforin käyttäytymistä. Orgaaniset fosforiyhdisteet pystyvät kuitenkin sitoutumaan fosfaatti-ionien tapaan oksidipinnoille, jolloin niiden hajotus heikkenee. Sitoutumislujuus vaihtelee kuitenkin yhdisteestä riippuen. On valitettavaa, että orgaanisen fosforin merkitystä on selvitetty Suomessa hyvin vähän, vaikka eloperäisillä lannoitusaineilla on keskeinen rooli esim. luomuviljelyssä ja nimenomaan lannan fosfori aiheuttaa ympäristöongelmia intensiivisessä karjataloudessa.

\section{Mobilisoitumisreaktiot}

Maaveden liukoinen fosfaatti on kasveille käyttökelpoista, mutta sen pitoisuus ei riitä vastaamaan kasvien tarvetta ja maaaineksesta on vapauduttava fosforia täydentämään ravinteiden oton aiheuttamaa vajausta. Tämä puskurimekanismi toimii sitä paremmin, mitä täydempiä hiukkaspinnat ovat. Pidätyspintojen täyttyessä fosforin sitoutumistapa muuttuu ja sitoutumisvoimakkuus pienenee. Sama vaikutus on myös kilpailevilla ioneilla, joilla on taipumus sitoutua samoille pidättymispaikoille kuin fosfori. Tärkeimpiä kemiallisia kilpailijoita ovat humusaineet ja silikaatti. Humus edistää fosforin hyväksikäyttöä myös fysikaalisesti parantamalla maan rakennetta, jolloin kasvien laaja juuristo hyödyntää ravinnereservejä suuremmasta maatilavuudesta.

Puskurointireaktiot selittävät myös eroosioaineksesta aiheutuvaa vesistöjen 
kuormittumisriskiä. Normaalioloissa maaveden määrä kiintoainekseen nähden on pieni ja sen sisältämä fosforimäärä siten varsin pieni. Kun veden määrä kasvaa tulvan tai pintavirtailun seurauksena, maaveden fosfori- ja suolapitoisuus samalla pienenee. Tämän seurauksena maaaines alkaa luovuttaa fosforia ympäröivään veteen ylläpitääkseen tiettyä fosforin pitoisuutta. Mitä vähäsuolaisempaa vesi on, mitä enemmän vettä on ja mitä täydempiä hiukkaspinnat ovat, sitä enemmän maa-aineksesta vapautuu fosforia. Toisin sanoen tulva ja pintavirtailu muuttavat olosuhteita fosforin vapautumista suosiviksi, mikä korostaa toimivan ojituksen merkitystä vesiensuojelussa.

\section{Fosforin käyttökelpoisuuden parantaminen}

Koska suomalaisissa maissa on vähän luontaisesti käyttökelpoista fosforia ja paljon fosforin sitoutumista edistäviä tekijöitä, kasvien fosforinsaannin edistämiseksi olisi pyrittävä hyödyntämään kaikkia keinoja, joilla fosforin hyväksikäyttöastetta voitaisiin nostaa. Tehtävä ei ole helppo, mutta ainakin teoriassa siihen voitaisiin pyrkiä käyttäen hyväksi tietoa fosforin pidättymismekanismeista ja niihin vaikuttavista tekijöistä.

1) Pidättymisen pH-riippuvuutta on mahdollista käyttää hyväksi paitsi kalkituksen, myös lannoitteiden koostumuksen avulla. Laboratoriokokeissa on $\mathrm{mm}$. havaittu, että urean lisääminen maahan typenlähteeksi lisää maan fosforivarojen liukoisuutta (Hartikainen ja Koivunen 1990, Hartikainen ja Yli-Halla 1995). Ilmiö johtuu nopeasta pH:n noususta urean hajotessa vapautuvan ammoniakin seurauksena, mikä edistää fosforin mobilisoitumista oksidipinnoilta. Kokeet osoittivat, että vaikka maan $\mathrm{pH}$ alkaa laskea ammonium-typen muuttuessa nitraatiksi, fosforin pidättyminen takaisin maahiukkasten pinnalle ei käynnisty samaa tahtia. Nitrifikaation estoaineet pitivät fosforikonsentraation korkealla melko kauan, koska pH:n alenemista ei päässyt tapahtumaan. Happamasti reagoivien fosforilannoitteiden voidaan olettaa olevan huonompia kasvien kannalta kuin emäksisesti reagoivien. 2) Fosforin pidättymisen riippuvuutta maanesteen suolaväkevyydestä voitaisiin käyttää hyväksi lannoitteiden matriisia suunniteltaessa. Voidaan olettaa, että mitä vähemmän lannoitteessa on kasvien kannalta tarpeettomia suoloja, sitä edullisempi se on kasvien fosforin saannin kannalta. NPK-lannoitteiden käyttö saattaakin edistää fosforin pidättymistä suolaväkevyyden vuoksi. Toisaalta lannoitteisiin voitaisiin lisätä anioneja, jotka vähentäisivät fosforin pidättymistä kilpailemalla samoista pidättymispaikoista. 3) Maanesteen suuri hetkellinen fosforipitoisuus lannoituksen jälkeen edistää fosforin pidättymistä. Tätä ilmiötä voitaisiin pyrkiä välttämään kehittämällä hitaasti fosforia luovuttavia lannoitteita.

Lannoitteiden kehittäminen ei siis ole menettänyt ajankohtaisuuttaan, vaikka lannoitefosforin käyttömäärät ovat viime vuosina pienentyneet. Päinvastoin, mitä vähemmän lannoitefosforia käytetään, sitä tärkeämpää on, että hyväksikäyttöaste olisi korkea. Korkean hyväksikäyttöasteen kääntöpuolena saattaa olla mahdollisesti erodoituvan maa-aineksen aiheuttaman rehevöitymisriskin kasvaminen. Vaikka fosforin käyttökelpoisuuteen ja ympäristövaikutuksiin liittyviin ongelmiin siis haettaisiinkin ratkaisuja liukoisten fosforifraktioiden käyttäytymisestä, ei eroosiontorjuntaa pidä jatkossakaan unohtaa.

\section{Fosfori ja pellon vesitalous}

Fosforin liikkuminen maassa ei ole yhtä suoraviivaisesti riippuvainen veden liikkeistä kuin nitraatin. Pellon vesitaloudella on kuitenkin huomattava rooli fosforin reaktioiden ja kulkeutumisen säätelyssä. Riisipelloilta tuttua on, että veden kyllästämissä oloissa fosforia vapautuu raudan sitomasta fraktiosta, sillä pelkistävissä olosuhteissa rautaoksidit menettävät kykyään sitoa fosforia. Osa vapautuneesta fosforista voi sitoutua takaisin maahiukkasten alumiinioksideihin, mutta osa jää liukoisena maaveteen. Suomessa vastaava tilanne lisää liukoisen fosforin huuhtoutumisriskiä pintavirtailuvesien mukana. Lisäksi on huomattava, 
että veden vaivaamissa maissa kasvien kasvu on heikkoa eikä mikrobiologinen hajotus toimi tehokkaasti, joten sekä epäorgaanisten että orgaanisten ravinnereservien hyödyntäminen jää heikoksi. Myös pintavalunnan aiheuttama eroosioriski on suuri heikosti vettä läpäisevillä mailla.

Veden liikkeiden ja ojituksen vaikutusta fosforin liikkumiseen on tutkittu viime aikoina laajassa yhteistyöprojektissa, jossa on ollut mukana Helsingin yliopisto, Teknillinen Korkeakoulu ja Maa- ja elintarviketalouden tutkimuskeskus. Yliopiston vastuulla on ollut selvittää salaojaveden liukoiseen fosforiin vaikuttavia tekijöitä. Koska valumavesi läpäisee erilaisia maakerroksia (horisontteja) matkalla salaojaan, olettamuksena on, että salaojaveden fosforipitoisuus määräytyy kerrosten fosforinpidätysominaisuuksien mukaan. Eri horisonttien sitomiskyvystä tehdyt mittaukset antoivat pidättymis- ja mobilisoitumisteorioita tukevia tuloksia. Mobilisoituminen oli tehokkainta pintamaissa, joihin fosforia oli aikojen kuluessa kertynyt eniten fosforia. Eniten pidätyskykyä oli heti muokkauskerroksen alapuolella olevissa kerroksissa ja vähiten pohjamaissa, joissa rapautuminen ei ole edennyt yhtä pitkälle kuin ylemmissä horisonteissa eikä aktiivista pidätyspintaa ollut ehtinyt syntyä.

Näiden tulosten suoraviivainen tulkinta olisi, että syvempien maakerrosten suuri fosforinsitomiskapasiteetti pitää pitoisuudet salaojavesissä hyvin pieninä. Käytännössä kuitenkin salaojavesissä voi olla varsin korkeitakin fosforipitoisuuksia. Tämä ilmiö selittyy sillä, että veden virratessa halkeamia tai suuria huokosia pitkin alaspäin se pääsee kontaktiin vain hyvin rajallisen maatilavuuden kanssa. Jos veden virtausnopeus on lisäksi suuri, fosforin vaihdossa ei ehdi syntyä tasapainoa vesifaasin ja kiintoaineksen välillä. Näin ollen pintamaan ominaisuudet heijastuvat vajoveden koostumukseen selvemmin kuin pohjamaan. Pahimmillaan sateen alla tehty fosforilannoitus voi kohottaa salaojaveden fosforipitoisuuden huomattavan korkeaksi. Veden liikkeiden hidastaminen esimerkiksi säätösalaojituksen avulla parantaa maaveden kontaktia kiintoaineksen kanssa, minkä voidaan olettaa vähentävän fosforin huuhtoutumista. Laboratoriossa tehdyt padotuskokeet viittaavat tähän suuntaa, mutta aihetta pitäisi tutkia myös käytännön mittakaavassa.

\section{Tutkimuksen haasteita}

Maan fosforivarojen saaminen tehokkaaseen käyttöön sekä lannoitusaineiden fosforin hyväksikäyttöasteen parantaminen ovat edelleen tutkimuksen suuria haasteita. Niihin pitäisi voida vastata sekä ympäristönsuojelullisten että taloudellisten näkökohtien vuoksi. Fosforilannoitteiden käytön minimointi - mahdollisimman tehokas käyttö - on paitsi vesistöjen ja maapallon raaka-ainevarojen, myös viljelijän kannalta hyvä tavoite, kunhan se ei aiheuta kohtuuttomia menetyksiä satotasossa. Orgaanisen fosforin dynamiikkaa maassa ei hallita yhtä hyvin kuin epäorgaanisen ja siihen pitäisi jatkossa panostaa enemmän. Maatalouden ravinnekuormituksen pienentämiseksi viljelykäytäntöjä pitäisi kehittāä siihen suuntaan, että kuormituspiikit, joissa suuri osa tappioista tapahtuu, saataisiin leikatuiksi pois. Ympäristötukiehtojen mukaisista toimenpiteistä suuri osa painottuu pintavalunnasta ja eroosiosta aiheutuvien haittojen torjumiseen. Kaikki kiintoaineksen kuljettama fosfori ei kuitenkaan aiheuta välitöntä rehevöitymisuhkaa. Ehkä enemmän huomiota täytyisikin kohdistaa mekanismeihin, jotka säätelevät välittömästi biologisesti käyttökelpoisen tai helposti mobilisoituvan fosforin kulkeutumista vesistöihin. Näiden mekanismien hallintaan liittyy olennaisesti maan myös vesitalouden hallittu säätely.

\section{Kirjallisuus:}

Hartikainen, H. \& Koivunen, M. 1990. Mobilization of soil phosphorus as induced by urea hydrolysis. Trans. $14^{\text {th }}$ Intern. Congr. Soil Science Vol 2, commission 2: 204- 209.

Hartikainen, H. \& Yli-Halla, M. 1995. Solubility of soil phosphorus as influenced by urea. Z. Pflanzenernähr. 
Bodenk. 159: 327-332.

Peltovuori, T. 2000. Horisonttien fosforinpidätysominaisuuksien vaikutus liukoisen fosforin huuhtoutumiseen salaojavalunnassa. Salaojituksen Tutkimusyhdistyksen tiedote 24: 4-9.

Soinne, H. 2000. Maan jäätymisen vaikutus fosforin pidättymiseen. Pro gradu. Helsingin yliopisto, Soveltavan kemian ja mikrobiologian laitos. $56 \mathrm{~s}$. 